\title{
A REVIEW OF THE USE OF IMMUNE SERUM IN ACUTE POLIOMYELITIS
}

\author{
BY \\ JAMES M. SMELLIE, M.D., F.R.C.P. \\ (From the Children's Hospital, Birmingham.)
}

Poliomyelitis is an acute infection of the central nervous system, with an incubation period of from 7 to 14 days, and its highest incidence in the summer and early autumn (July to October). It is characterized by an abrupt onset with fever and marked constitutional and nervous symptoms: these develop rapidly and rarely last more than a few days. Although this is usually termed the pre-paralytic stage, it is, in actual fact, the active period of the disease. These symptoms terminate quite abruptly with the appearance of the paralysis. Then, in reality, the disease is over, and treatment from this stage onwards is of a passive character (Ayer $\left.{ }^{3}\right)$.

Active measures, therefore, to be of any value must be instituted prior to the development of the paralysis, and this is the aim and object of treatment by means of ' convalescent serum.'

During the last several years a large amount of work has been carried out, particularly in America and Australia, and there have been innumerable publications on the use of convalescent serum in the treatment of poliomyelitis. It is instructive, therefore, to review briefly this large mass of work and to attempt to assess the value of this line of treatment.

All writers emphasize the fact that the cases must be diagnosed and treated in the pre-paralytic stage if beneficial results are to be obtained. Poliomyelitis is due to a true filtrable virus, and no disease due to a filtrable virus is known to be benefited by an antiserum after clinical symptoms have developed $\left(\right.$ Park $\left.^{15}\right)$. Unfavourable opinion of serum therapy has been created by delay and consequent unsuccessful administration in the presence of paralysis. At such a stage it is wasteful and futile to inject serum. Unless this fact is constantly borne in mind there is real danger that a most valuable therapeutic advance may fall into disrepute.

The pre-paralytic stage.-An essential criterion, therefore, for successful serum therapy is the diagnosis of poliomyelitis in its acute, or so-called pre-paralytic, stage. This stage presents a definite chain of symptoms and physical signs which can be recognized. In many cases, particularly in the presence of an epidemic, it is possible to be reasonably certain of the diagnosis on clinical grounds alone, but the diagnosis should never be made and serum. treatment should never be instituted until the cerebro-spinal fluid has been examined. 
Under these circumstances too much insistence cannot be placed on early diagnosis and the manifestations of the acute phase are worthy of consideration in detail. This acute phase usually lasts from 24 to 48 hours. The most typical early and constant symptom is fever, and though this is rarely above $102^{\circ}$ the child is more prostrate than the temperature would indicate. Severe headache, pains in the neck, back and elsewhere, one or two attacks of vomiting, apathy, indifference and drowsiness are other commop symptoms. The child may appear to be irritable when roused, but careful examination will reveal that this is really due to hyperæsthesia and muscular rigidity.

Of physical signs the most important is rigidity of the neck muscles. This is rarely so severe as to cause definite head retraction, and in fact may not be evident unless specifically searched for. In passing it is interesting to record that the importance of this sign was recognized by one of the earliest describers of the disease, namely Medin; and in fact even to-day poliomyelitis is popularly called the ' neck disease' in Sweden. This rigidity of the neck muscles has received various designations, and may be elicited in various ways. If the child is not too ill to co-operate in the examination he may be asked to pick up a penny from the floor or to kiss his knee. A willing child will attempt the necessary movement but will fail to complete it on account of pain or discomfort. Again, when the child is placed in the sitting position, the hands are placed behind the body to support it (Amoss's sign). Another test is to ask the child to touch his sternum with his chin (the chin sign); a child in the pre-paralytic period will try to do this by opening the mouth. What these various tests reveal is the unwillingness of the child to flex the spine. Other physical signs are a rapid pulse rate, out of all proportion to the temperature. There may also be fine tremor of the hands and lips, and the deep reflexes are often increased in the early stages. Constipation is the rule. Retention of urine, photophobia, and sweating of the face and neck are less commonly observed. Some authors (Ayer ${ }^{3}$ ) say that coma and convulsions do not occur; but others (MacNamara and Morgan $^{13}$ ), whilst admitting that they may occur, qualify this by stating that repeated convulsions suggest another diagnosis.

It is obvious from this description that on clinical grounds alone the differential diagnosis must frequently be a matter of great difficulty and often impossible. The important point, however, is that if the clinical picture in any way suggests the diagnosis of acute poliomyelitis, lumbar puncture must be performed and the cerebro-spinal fluid examined both cytologically and biochemically.

The cerebro-spinal fluid usually flows out under a slightly increased pressure, it is clear unless the cell content is very high, when a slight haziness may be discernible. The cytology of the fluid is of great diagnostic importance. Most cases of poliomyelitis show a cell count between 50 and 200, but counts up to 700 have been recorded. The count may be affected by the severity of the infection and the time of lumbar puncture. The types of cell present have been found to be different by different observers, in, it 
should be added, different epidemics. Thus, MacNamara and Morgan ${ }^{13}$ state that early in the pre-paralytic stage the polymorphonuclear cells are increased, but they disappear as the lymphocytes increase until, at the stage of paralysis, only 5 to 10 per cent. of the cells are polymorphonuclears. Thelander, Shaw and Limper ${ }^{18}$, on the other hand, found that the average percentage of polymorphonuclear cells in the fluid in the first five days of the disease was about 50 per cent. and that their percentage was independent of the day of the disease. They appreciate that their findings are not in accordance with those of most authors, and suggest that this may be accounted for by variations in different epidemics and by the technique of staining and studying the cells.

It is evident from these results, therefore, that in some cases at any rate the differential diagnosis, particularly between poliomyelitis and tuberculous meningitis, may be impossible by cytological examination alone. Consequently, the necessity for biochemical examination becomes obvious. The protein content of the fluid is increased in both these diseases, so again for differential diagnosis this observation is of no value. Estimation of the chloride content, however, is of very considerable importance. In poliomyelitis the chloride content of the cerebro-spinal fluid is not disturbed (730 mgrm. per cent.). In the vast majority of cases of tuberculous meningitis, on the other hand, the chlorides are appreciably reduced. It is true that occasionally a normal or even high chloride content may be found in tuberculous meningitis (Neale and Esslemont ${ }^{14}$ ), but as this occurs late in the disease there is no real likelihood of confusion.

To recapitulate briefly, the characteristic findings in the cerebro-spinal fluid are (1) an increased cell content; (2) normal chloride content, and (3) increased protein; and as Gordon ${ }^{7}$ has expressed it, the diagnosis of pre-paralytic poliomyelitis consists of a healthy clinical suspicion and a lumbar puncture.

\section{Immune serum.}

The employment of convalescent human serum in the early treatment of poliomyelitis is founded upon sound experimental evidence in monkeys. Flexner and Lewis ${ }^{4}$ (1910) were the pioneers in this field and during the next few years their results were confirmed by other observers. These investigators showed that if the virus of poliomyelitis was mixed with convalescent serum and injected into monkeys, no paralysis developed ${ }^{16}$. Further, monkeys inoculated with the virus intra-cerebrally or intra-nasally could be protected from developing the paralytic stage by the intra-spinal injection of convalescent serum, even if the serum was injected as long as 18 to 24 hours after the virus. It is important to note that these workers found that equally satisfactory results could be obtained with either convalescent monkey or convalescent human serum, but that normal (i.e., non-immune) monkey and normal human serum was without any appreciable effect ${ }^{15}$, 
These experiments, then, form the basis for the use of convalescent serum therapeutically in man.

The serum of a person who has had poliomyelitis has been demonstrated to possess high viricidal properties for many years afterwards. In fact, from the few experiments that have been conducted, the lapse of time would not appear to reduce its potency to any appreciable extent, Moreover, there is some evidence that individuals belonging to blood-group 2 are, on average, more resistant to poliomyelitis than those of other groups and their serum has proved, in a few instances, to be more effective in neutralization tests, than serum from donors of other groups ${ }^{17}$. From the published evidence it seems wise to wait some months after the attack of poliomyelitis before using the blood of that patient for therapeutic purposes, but the best time to collect the serum has not yet been ascertained. It is true that the blood of some people who have not had the disease clinically also possesses neutralizing properties, which may be the result of an abortive and unrecognized attack, or from repeated sub-minimal infections in childhood, but this cannot be depended upon without testing. Such testing necessitates carefully controlled animal experiments and until this can be carried out on a wide scale it is best to use only serum from known clinical cases, at any rate for curative purposes.

As the severity of the original infection bears no known relationship to the subsequent viricidal concentration of the serum, the blood of mild cases can, in the present state of knowledge, be regarded as equally efficacious as that from even the most severe cases. There is one other important point in this connexion; it is now known that there are several varieties of poliomyelitis virus, so it is wise to use pooled serum from different cases and from different epidemics if the most satisfactory results are to be achieved.

Preparation of serum.-In the preparation of the serum MacNamara and Morgan ${ }^{13}$ advise that no antiseptic be added, as they consider that this may be the cause of certain unfavourable reactions that have been noted after the injection of the serum. In America, on the other hand, some antiseptic is usually added. Such serum, carefully prepared, has been stored for over three years without evident deterioration of its potency.

Methods of administration and dosage of serum.-The diagnosis of the pre-paralytic stage having been established, the injection of immune serum is a matter of extreme urgency. The treatment is a true medical emergency. In actual practice it is preferable to perform lumbar puncture, withdraw a few cubic centimetres of fluid and leave the needle in situ while the fluid is being examined. If the diagnosis is confirmed, serum may then be administered intrathecally without delay, and the patient is saved the discomfort of a second puncture. Coincident with this intrathecal injection serum should also be given intravenously.

It must be remembered that the aim of treatment with convalescent serum is to produce a passive immunity. The initial dose, therefore, should be high, the amount depending not on the age of the patient but rather on 
the duration and severity of the symptoms. Intrathecally the amount injected should be slightly less than the quantity of cerebro-spinal fluid withdrawn. An intravenous injection is equally effective, but there must be a certain delay in it reaching the central nervous system, and time is a matter of considerable importance.

The total initial dose of serum, i.e., intrathecally and intravenously, recommended varies from about 25 to $100 \mathrm{c.cm}$. , and if there is no improvement in 18 to 24 hours this dose should be repeated.

Results of serum therapy.-To analyze critically the published results of the serum treatment of poliomyelitis is no easy task. By no means all patients who contract this disease develop paralysis, and there must be an appreciable number of such in every series of published cases treated with serum. Another point to be remembered is that the physical signs and symptoms in the pre-paralytic stage do not give any indication of what the ultimate outcome will be $\left(\right.$ Aycock $\left.^{1}\right)$; in other words, there is no relationship between the severity of the pre-paralytic symptoms and the extent of the ensuing paralysis. Further, in every series of serum-treated cases the question of accuracy of diagnosis arises.

Poliomyelitis varies in its virulence as do all epidemic diseases, so that extreme caution must be exercised in comparing results of treatment in different places at the same time, or in the same locality in different epidemics.

A brief epitome of a few of what seem to me the more important published papers will serve to define best the present position and opinions of serum therapy.

In 1928 Aycock and Luther ${ }^{2}$ published the results of the treatment during the first 4 days of the disease of 106 children in whom paralysis had not appeared. The serum was administered intrathecally and intravenously. One child died and 64 per cent. of the remainder developed some paralysis, but the average total paralysis in the serum-treated cases was very considerably lower than in 483 untreated cases reported in the same year. In fact, only 5.7 per cent. of the treated cases developed severe paralysis, in comparison with 46 per cent. of the untreated ones. These authors concluded that the administration of convalescent scrum in the pre-paralytic state exercised a favourable effect on the subsequent course of the disease.

Kellog', in 1929, critically analyzed what he considered to be the more important published results. His conclusions were that convalescent serum was of value in the treatment of poliomyelitis, and that its use should be encouraged and extended.

Early last year (1932) a most important and instructive paper was published by Kramer and Aycock ${ }^{11}$. They endeavoured to test the results of serum therapy by way of a controlled experiment and failed to obtain statistical evidence that convalescent serum produced any appreciable effect. There was no evidence to show that the serum was of no value, and they considered that there is justification for its employment on a larger scale, 
In 1931 in the State of New York 1,019 cases of poliomyelitis were diagnosed in the pre-paralytic stage $\left(\mathrm{Park}^{16}\right) ; 572$ were treated with serum and the remainder received no serum, yet there was no appreciable difference in the results of the two groups. Nevertheless, the opinion was expressed that serum should continue to be used.

In Australia, MacNamara and Morgan ${ }^{13}$ have been studying this problem for some years. In their hands the use of human immune serum, administered in the pre-paralytic stage, has given excellent results, as evidenced by a low mortality rate, a low average total paralysis and a strikingly low proportion of paralysis of the severer grades. They further state that if ample serum is available its administration within 24 hours of the development of paralysis to a febrile patient is justified, and is usually followed by a fall of temperature and arrest of paralysis. If given later, when paralysis is stationary, serum is of no value.

Whilst most writers on this subject are guarded in expressing their conclusions on statistical evidence, the impression is gained from reading their papers that those who had most experience with serum do feel that a strong case has been made out for its employment and ample justification exists for its continued and extended use.

To the punctilious statistician ruthless alternation of cases would be the only way of obtaining conclusive information. But, as is so well put by Kellog9, a physician dealing with the lives of children instead of guinea-pigs naturally shrinks from such a procedure if he has any confidence at all in the treatment under investigation.

Prior to the introduction of immune serum, the study of poliomyelitis in its pre-paralytic stage received scant attention. With the advent of serum therapy, however, great impetus was given to the study of the acute manifestations with the result that much further knowledge has been gained. In this connexion it has been suggested that the term ' infantile paralysis' is misleading, as paralysis is an incidental and not an essential result of the infection. It is now beginning to be realized that poliomyelitis has a much greater incidence than has been appreciated in the past. For instance, in every epidemic it is now appreciated that there is no inconsiderable number of abortive and non-paralytic cases, which has been assessed as high as 50 per cent. in some epidemics. Again, small epidemics of an acute febrile disorder of an influenza-like type, of short duration and with no sequelæ, have been recognized as epidemics of poliomyelitis. For example, Paul in 1931 (see Poliomyelitis ${ }^{17}$, p. 178) found the poliomyelitis virus in 2 out of 12 cases of minor illness, which cases did not subsequently show any signs by which the diagnosis of poliomyelitis might be made.

It follows, therefore, that until poliomyelitis in all its clinical aspects has been completely elucidated, the value of immune serum, its uses and its limitations cannot possibly be estimated with scientific accuracy.

If further knowledge is to be gained immune serum must be used much more extensively, but care should be taken to ensure that it is only used in the right cașes and at the right time. 
Lumbar puncture.

The place of lumbar puncture in the treatment of pre-paralytic poliomyelitis is worth brief consideration for several reasons. This, again, is a subject about which different views are held in America and in Australia.

First of all, it has been proved experimentally that an intact choroid plexus offers an important barrier to the ingress of the virus to the brain and spinal cord. Conversely, anything which causes damage to the plexus by setting up what is commonly called an aseptic meningitis or meningismus (e.g., sterile horse serum) allows the virus to penetrate more readily.

MacNamara and Morgan ${ }^{13}$ are not in favour of lumbar puncture. In several of their cases that failed to respond to serum treatment there was a delay between the withdrawal of a large quantity of cerebro-spinal fluid and the administration of serum. They suggest that the withdrawal of large quantities of fluid during the pre-paralytic stage may have actually determined involvement of the spinal cord. Gordon ${ }^{7}$ also issues a warning against lumbar puncture, as he fears that it may initiate involvement of the central nervous system by enabling the virus to penetrate the choroid plexus more readily.

Contrary. views, however, are expressed by most American workers. In the Report of the International Committee ${ }^{17}$ many American physicians are quoted as being very definitely in favour of lumbar puncture, per se, as a therapeutic measure, in fact it is held to be extremely valuable. As is pointed out, the cerebro-spinal fluid is usually under increased pressure, consequently the relief of this pressure by lumbar puncture is a rational procedure. These authors all noted a marked improvement in symptoms which invariably followed the withdrawal of fluid, namely, the cessation of vomiting, diminution in the rigidity of the spinal muscles and abatement of the hyperæsthesia. Some even go so far as to say that the relief of pressure may exercise a favourable influence in preventing the development of the paralysis or at least in modifying its progress.

Neither the Australians nor the Americans state how much fluid should be withdrawn. It should be noted, however, that MacNamara and Morgan ${ }^{13}$ refer to the withdrawal of large quantities of fluid, which quite conceivably could do harm by damaging the choroid plexus. If, on the other hand, only sufficient fluid is allowed to escape to permit the pressure to return to normal, benefit and not harm may accrue. It is suggested that this may be the reason for the different opinions expressed.

\section{Prophylactic treatment with immune serum.}

Information on this point is meagre bu: important. The remarks of Miss Neal in the International Report ${ }^{17}$ are both interesting and instructive. During an epidemic in Sweden in 1925, Davide inoculated 73 children with serum and only one, who had obviously been infected before the injection, developed the disease, which incidentally ran a mild course. Out of 84 
that were not inoculated 14 developed poliomyelitis. In New York ${ }^{16}$, in 1931, several hundred children received passive immunization and only 3 mild cases developed. In Bradford, U.S.A. ${ }^{17}$, 1,300 children were inoculated with whole blood and none developed poliomyelitis, although 32 uninoculated children did contract the disease.

With regard to dosage, the Swedish children received $5 \mathrm{c.cm}$. of convalescent serum intramuscularly. The Americans advise 20 c.cm. of serum; or, if convalescent serum is not available, normal or adult serum or whole blood may be used in larger doses. A third method of passive immunization is that of utilizing refined immune horse serum. As this serum has a higher neutralizing power, $10 \mathrm{c.cm}$. intramuscularly is considered an adequate dose.

Passive immunization thus produced lasts not more than 3 weeks with human serum and about 2 weeks with horse serum. During an epidemic, therefore, repeated doses may be necessary. When using horse serum the possibility of serum sickness and hyper-sensitiveness must be borne in mind.

Thus evidence is accumulating to show that passive immunization against poliomyelitis is of value as a prophylactic measure, and has something to commend it. It seems unlikely that supplies of convalescent serum in this country will be available for this purpose for some time to come. Fortunately, it has been proved that in some parts of the world, at any rate, the serum of many adults is equal in neutralizing power to that of convalescent serum. For prophylactic purposes, therefore, in the presence of an epidemic nothing but benefit can accrue from the injection of adult serum or whole blood into known or suspected contacts. This should be adopted widely under carefully controlled conditions in order that its efficacy may be put to practical trial on an extensive scale and its value accurately assessed.

\section{Summary and conclusions.}

1. The diagnosis of poliomyelitis in its acute or pre-paralytic stage is an essential criterion for successful treatment by immune (convalescent) human serum.

2. This pre-paralytic stage presents a chain of symptoms and physical signs which can be recognized.

3. Lumbar puncture, with cytological and biochemical examination of the cerebro-spinal fluid, is necessary to establish the diagnosis and immune serum should not be administered until this has been done.

4. The employment of convalescent serum in the treatment of acute poliomyelitis is founded upon sound experimental data in animals.

5. The serum of a person who has had poliomyelitis has been demonstrated to possess high neutralizing properties for many years thereafter. Further, the blood of adults who have not suffered from the disease clinically may also possess neutralizing properties. 
6. Whilst the statistical evidence in favour of immune serum is far from convincing, those who have had most experience with this form of treatment feel that a strong case has been made out for its employment and ample justification exists for its continued and extended use.

7. The place of lumbar puncture in the treatment of pre-paralytic poliomyelitis has not yet been settled. The withdrawal of sufficient fluid to allow the pressure to return to normal is probably of value in preventing the development of paralysis or at least in modifying its progress.

8. Evidence is accumulating to show that passive immunization against poliomyelitis may be of value as a prophylactic measure.

9. Much work yet remains to be done with regard to both the study of the acute disease as well as its treatment by immune serum before the many at present perplexing problems can be solved.

\section{REFERENCES.}

1. Aycock, W. L., J. Am. Med. Ass., Chicago, 1932, XCIX, 1056.

2. Aycock, W. L., \& Luther, E. H., Ibid., 1928, XCI, 387.

3. Ayer, W. D., Am. J. Med. Sc., Philad., 1929, CLXXVII, 540.

4. Flexner, S., \& Lewis, A., J. Am. Med Ass., Chicago, 1910, LIV, 1780.

5. Flexner, S., \& Stewart, F. W., Ibid., 1928, XCI, 383.

6. Flexner, S., \& Stewart, F. W., New Eng. Med. J., 1928, CXCIX, 213.

7. Gordon, J. E., J. Am. Med. Ass., Chicago, 1932, XCIX, 1043.

8. John, R. L., Am. J. Dis. Child., Chicago, 1931, XLII, 480.

9. Kellog, W. H., J. Am. Med. Ass., Chicago, 1929, XCIII, 1927.

10. Kramer, S. D., Ibid., 1932, XCIX, 1048.

11. Kramer, S. D., \& Aycock, W. L., New Eng. Med. J., 1932, CCVI, 432.

12. Levinson, S. O., McDougall, C., \& Thalhimer, W., J. Am. Med. Ass., Chicago, 1932, XCIX, 1058.

13. Macnamara, J., \& Morgan, F. G., Lancet, Lond., 1932, i, 469.

14. Neale, A. V., \& Esslemont, M. S., Arch. Dis. Childh., Lond., 1928, III, 243.

15. Park, H. P., J. Am. Med. Ass., Chicago, 1932, XCIX, 1050.

16. Park, W. H., Lancet, Lond., 1932, ii, 186.

17. Poliomyelitis, Rep. Internat. Com., Baltimore, 1932.

18. Thelander, H. E., Shaw, E. B., \& Limper, M., Am. J. Dis. Child., Chicago, 1931, XLII, 1117.

19. Silverman, A. C., Ibid., 1931, XLI, 829. 